\title{
The Problems and Strategies in Improving the Universities' Independent Innovative Abilities
}

\author{
Hui LIN ${ }^{1}$, Lijuan WANG ${ }^{1}$, Qin SUN ${ }^{1}$,Yanfeng TIAN ${ }^{2,3}$, Changsheng \\ $\mathrm{ZHAO}^{1}$, Congying SHAO
}

${ }^{1}$ Jiangsu normal university institute of surveying and mapping, Xuzhou, Jiangsu, 221116

${ }^{2}$ China university of mining environment and institute of surveying and mapping, Xuzhou,Jiangsu, 221116

${ }^{3}$ The air force service institute of airport engineering, Xuzhou,Jiangsu, 221110

Keywords: universities' independent innovative abilities; innovation; fundamental research; scientific research achievements conversion; intellectual property

\begin{abstract}
The universities' independent innovative abilities have polarized a lot recently, universities with high scientific research ability are developing at a high speed, but they ignore the fundamental research and the low scientific research achievements conversion rate; The independent innovative abilities of ordinary universities develop slowly because of the lack of high level and energetic teachers. This paper analyzed current construction conditions of independent innovative abilities, pointed out the most important problems in improving innovation abilities, and then proposed that the innovation abilities should be improved from seven aspects: scientific research direction, discipline construction, property consciousness, personnel training, operation mechanism optimization, production and research integration and innovation of science and technology achievements transformation model.
\end{abstract}

Project funding: National Natural Science Foundation(41401397) Graduate education teaching reform research and practice in Jiangsu province in 2014 (146), the key course construction project of Jiangsu normal university(28), Jiangsu normal university educational reform (XJG201208, XJG201249 )

To strengthen independent innovation is the strategic point of building an innovative country and developing science and technology. And the university is undertaking the dual task of knowledge innovation and knowledge dissemination, it is the main force in the construction of innovative country[1]. Over the years, China's universities have trained a large number of outstanding talents, and made a lot of scientific and technological achievements. What's more, they have become an important part of the national innovation system. At the same time, we should also be aware of the realistic problem.

"Wholesale" education has become the main guidelines, and the teaching staff construction, the universal participation and the education reform have been ignored. With the sharply increasing enrollment, scientific researchers with innovation ability have no significantly increased, which shows that there is a big gap in training innovative talents in the aspects such as scientific research method. And innovative changes should be made. 


\section{The present situation of universities' independent innovative abilities construction}

Talent training quantity increased with the relative lack of innovative talents

In 2013, the national ordinary universities and training schools received total enrollment of 6.888 million students, recruited 608,000 graduate students, including 69000 doctoral students and 539,000 master students. Compared with 1998, this specialized subject graduates is 6.35 times that of 1998, and graduate student enrollment is 8.38 times that of 1998. Although the number of college recruit students increased, the social demand for high level creative talents were not fundamentally met. On the one hand, a lot of college students still have employment difficulties, and the need for innovative talents cannot be satisfied, which fully shows that the cultivation of innovative talents in universities needs to be strengthened.

Less original scientific research with low conversion efficiency

According to statistics, 2013 science citation index (SCI) included 1.7097 million articles, including 231,400 papers science and technology of China, for five consecutive years ranked second in the world; Engineering index included 163,500 Chinese papers, the amount came first in the world; Publications in Scopus China ranked second in the world; In 2014, countries around the world applied for 215,000 patents through the organization of the patent cooperation treaty (PCT) system, and China applied for 25539 patents, with $18.7 \%$ of the growth as the largest contributor, was meanwhile the only country who achieved double-digit growth. We also need to note the low conversion rate of scientific and technological achievements. According to the statistics from the state intellectual property office, from the aspect of the average maintain limitation of invention patent, domestic patent was 6.0 years, while foreign patent in China was 9.4 years.

More attention on heat specialties while neglecting the innovation

Since 2013, Liaoning province has suggested that universities suspend application for nearly more than 60 professionals, including economics, Chinese language and literature and so on. Many universities have added professional blindly just according to the professional popularity, ignoring the saturated talent market and the reality that the work is becoming relatively less. The innovative ability of education group is related to a country's level of creativity, "the Qian Xuesen question" has raised the reflection to innovative ability in China[2]. Some universities tend to apply for scientific research projects and focus on teachers' ability to publish papers. The university's professional settings also tend to the high employment rate of popular professional, and attach no importance to the education of innovative awareness. These phenomena show the low social service consciousness of some universities, and thus lose the essence of social development leaded by universities through cultural innovation.

\section{The main bottleneck affecting the promoting of universities' independent innovative abilities}

Innovation spirits and abilities are main factors restrict national innovation ability development, though many universities have contributed to promoting sci-tech progress and social development, it should be noticed that there are still many deficiencies in improving universities' independent innovative abilities. Many factors restrict the promotion of independent innovative abilities.

More attention on papers and prizes while less attention on fundamental research

The university can promote the overall development of an industry. However, many teachers focus on the numbers of their papers and neglect the quality of these papers, attach great importance to theoretical research with short-term results, and give up fundamental research needed long-term energy. For a long time, our country's foundation has lagged behind the western developed countries, the accumulation of original is relatively deficient at the same time; On the other hand, the research core stays in advanced technology research and achieve a number of results, but not many has the world influence.

The construction of teaching staff needs to improve

"The so-called university, not that there is a building, but there is the master." That is to say, the research level of faculty is the key to improve the universities' independent innovative abilities and 
the schools' development. Nowadays the teaching staff construction in universities mainly exist the following problems:

Changjiang scholars and other well-known scholars and researchers are mostly concentrated in the famous universities, higher levels and energetic teachers in common universities can hardly satisfy the needs of the school development, universities of high scientific research ability lack communication with common universities[3].

Scientific research consciousness is ambiguous, selfishness is heavy. Influenced by traditional concepts and treatment, many researchers are more willing to work alone. They are satisfied with a small amount of research funding.

Reserved talents are insufficient and the youth make little contribution to the teaching staff construction. Affected by work experience and qualifications, the incomes and treatment of young teachers are relatively low. Therefore, the attraction for young teachers to work in universities declines a lot which influences the construction of the reserved talents.

A certain degree of academic corruption

It should be acknowledged that there is a certain degree of academic corruption in scientific researches. In some universities, the reason why the academic bubble and academic corruption can't be stopped is closely related with the imperfect academic system. A few of universities lack the necessary scientific research standard and scientific academic evaluation mechanism, the offside of academic management, are likely to result in illusory academic prosperity and serious academic pollution, which are harmful to the development of academic research.

\section{Strategies to enhance the universities independent innovative abilities}

Construction of innovative and energetic university is the inevitably choice to participate in the innovation-oriented national construction, improve the level of school-running in universities and enhance their influence. In view of the current problems existing in the construction of universities, we should mainly focus on the following several aspects.

View the fundamental research as a long-term investment

For important scientific frontier direction, it is important to highlight the scientific goal and prospective layout, try to preempt the scientific high ground; For fundamental research of national development strategy, it is necessary to reflect the national will and focus on the future national competitiveness and strategic deployment. Therefore:

(1)The government should maintain the reasonable proportion of basic research, stabilize a batch of basic research team that serve long-term national goals.

(2)Promote scientific research institutions to implement the way of scientific and technological evaluation, and create a basic research environment that tolerates failure and encourages exploration.

(3)We should support and guide the enterprises to strengthen basic research. Through the research and development expenses plus tax incentives, enterprise state key laboratory construction, and other ways to guide enterprises, especially large enterprises to invest in basic research.

Concentrate on the cultivation of the reserve force of scientific research, improve training methods

Since the Ministry of education approved the establishment of Remote Sensing Science and technology as professional in 2002, as of 2014, more than 20 universities have set up the professional to train talents with the basic theory, knowledge and skills of remote sensing technology. Jiangsu normal university has stepped up the curriculum system and education reform, aiming to broaden the horizons of students and promoting the growth of talent through research. Undergraduate stage should implement "tutorial system"[4], "one to one study guide" training the ability of students to self-study, independent thinking. By creating a "teaching" and "learning" interactive environment, so as to improve students' learning objectives, stimulate their learning interest, broaden their knowledge, and enter into the scientific research.

Strengthen the talent team construction comprehensively

As the important base and the source of training innovative talents, universities should advocate 
and promote the concept of respecting knowledge and intellectuals, and to build a harmonious university science and technology innovation environment. Throughout the exploration, we must emphasize the construction from the following several aspects:

Building high-quality teaching staff. Universities should attach importance to the cultivation of scientific researchers and professional talents. Through multiple channels, it aims to establish a teaching staff with high research ability and teaching ability. To carry out the teaching resources sharing work, promote high quality teachers, professional and teaching materials, thus relative shortage of education resources in universities can be solved.

Universities of relevant advantages can carry out multilevel training lectures, and encourage universities with recruit graduate students qualifications to cooperate with enterprises and institutions according to the demand situation of universities[5].

Establish a mechanism for the conversion of scientific research findings at universities

We need to do the following efforts in the transformation of scientific and technological achievements:

Encourage universities to focus on social-oriented and market-oriented mechanism, strengthen the cooperation between enterprises, actively promote the use of intellectual property rights and transformation.

Establish a university intellectual property rights use transformation support mechanism. Universities are encouraged to use self imposed, patent licensing and other forms, to promote the implementation of the college patent technology. Give full play to the university science park into the implementation of independent intellectual property rights. The exploration of the intellectual property management work, the function of patent pledge financing mechanism, are helpful to promote the college patent technology commercialization and industrialization.

The reform of irrational scientific research evaluation and incentive mechanism should be carried out[6]. Through scientific evaluation, we can promote the optimization of scientific and technological resources to achieve the sharing of scientific research equipment and other scientific research conditions, bring out more excellent works, ensure the smooth implementation of the development goals and strategies of scientific and technological innovation ability in universities.

Actively carry out intellectual property publicity and education activities in colleges and universities

First of all, it is important for schools to mobilize the invention enthusiasm of teachers and students; Secondly, it is necessary to carry out the education of intellectual property rights in universities[7], spread patent awareness, the main measures are as follows:

Carry out the activities of intellectual property rights of students, and improve the scientific and cultural qualities of college students, improve the campus academic atmosphere in our province.

Establish university intellectual property rights volunteer team, carry forward the spirit of dedication, actively participate in the intellectual property services carried out by the intellectual property rights administrative departments, and give full play to the professional expertise of teachers and students, serve for the invention, intellectual property rights, social investigation and other public services [7].

Launch "Intellectual property into the campus" activities. During the 4.26 World Intellectual Property Day, all kinds of activities should be organized to broadcast intellectual property laws, regulations, policies and knowledge.

\section{Conclusion}

The independent innovation ability of university is the basic of national innovation ability, and it should strengthen the construction of University's own innovation ability from many aspects. It is important to relate to social needs and social development as the guidance and break through the current situation. For universities, the main direction of universities' exploration is the exploration and development of intellectual property rights, the role of the patent pledge financing mechanism, promotion of the commercialization and industrialization of university patent technology and outstanding scientific objectives; For talents, the most important quality is the ability to creatively 
respond to a diverse and changing environment[8]. We must innovate the mode of talent cultivation, establish new mechanism of innovation, use scientific and effective educational methods and means to open up the innovative thinking, ability, personality and spirit of the people to achieve the purpose of training and bringing up the talents.

\section{References}

[1] Zhu Yingxue, Dong Weiwu. Theory of establishing independent innovation system and mechanism in colleges and universities[J]. THEORY OBSERVE, 2009 , 04 : 112-114.

[2] Xue Eryong. Policy Analysis on Collaborative Innovation and Cultivation of Innovative Talents in Universities[J]. China Higher Education Research , 2012 , 12 : 26-31.

[3] Liu Hui. Research on teaching reform path based on the practice of applied innovative talents training-take the reform of university administrative management professional experiment teaching as an example[J]. Chinese journal of education , 2014,S5:169-170.

[4] Yu Zhongchen,Chen Ping,Li Fang,Lin Hongyan,Cui Hongmei. "Tutorial system" in the application and research of the education in colleges and universities[J]. China Electric Power Education,2014,02:15+30.

[5] He Ning. Bringing the Scientific Advantages of Colleges\&Serving the Local Economic and Social Development[J]. China Higher Education,2014,21:38-39+49.

[6] Li Erbin,Zhu Shigui,Qian Baoying,Deng Liqun,Liu Hao,Li Li.Establish and improve scientific research evaluation system, and promote the industry characteristic development and prosperity of humanities and social science in colleges and universities-take Nanjing agricultural university as an example[J].Management and Review of Social Sciences,2013,03:33-41.

[7] Wang Zhenyu,Zong Gang,Wang Zhenghu,Xia Nannan. The problems and causes of Chinese university intellectual property management and the policy improvements [J]. Studies in sciences of sciences,2012,10:1488-1493+1508.

[8] Mei Yuanhong,Liu Jia. Study on the Protection and Maintenance of Universities' Intellectual Property Strategy:A Case Study of Tsinghua University[J]. Science \& Technology Progress and Policy,2013,10:109-113. 